\title{
Tendencias electorales de los grupos indígenas en Chile
}

\section{Mauricio Morales Quiroga}

Doctor ( e en Ciencia Política. Director del Observatorio Político-Electoral, Instituto de Ciencias Sociales, Universidad Diego Portales.

\section{Jaime A. González G.}

Doctor ( e en Antropología. Académico de la Universidad Diego Portales.

RESUMEN | Relacionamos el porcentaje de voto por las principales coaliciones de Chile con el porcentaje de indígenas por comuna. Concluimos que existe una relación positiva entre concentración de población indígena y voto por candidatos de derecha. Sin embargo, la inclusión del territorio como variable explicativa cambia sustantivamente las interpretaciones. Así, en la primera región, con predominio de población aymara, a mayor porcentaje de indígenas por comuna, mejor desempeño electoral de los candidatos de derecha. En la novena región, en tanto, no hay una relación significativa entre porcentaje de mapuches por comuna y voto por la derecha. Probamos una serie de modelos estadísticos que confirman tales planteamientos en conjunto con evidencia histórica y entrevistas a informantes claves. Sugerimos que las diferencias electorales entre aymaras y mapuches obedecen a su disímil estructura sociopolítica, siendo históricamente más vertical en los primeros y más descentralizada en los segundos.

PALABRAS CLAVE | Política regional, transformaciones socioterritoriales, relación campo-ciudad.

ABSTRACT | We relate the votes for the main political coalitions' in Chile with the percentage of indigenous population. We conclude that there is a positive relationship between concentration of indigenous population and votes for right-wing candidates. However, the interpretations of this pattern are differentiated by including territory as an explanatory variable. Thus, in the first region, which is made up of a predominantly Aymara population and a larger percentage of indigenous communities, right-wing candidates tend to obtain morevotes. In the ninth region, there is no significant relationship between the percentage of Mapuche population and votes for right-wing candidates. We tested a series of statistical models that confirm such statements with historical evidence and interviews with key informants. We suggest that electoral differences between Aymara and Mapuche populations are due to their dissimilar socio-political structure, with the former being historically more vertical, and the latter more decentralized.

KEY WORDS | Regional policy, socio-territorial transformations, countryside-city relationship.

Recibido el 26 de julio de 2010, aprobado el 28 de enero de 2011.

Mauricio Morales agradece el financiamiento otorgado por la Universidad Diego Portales a partir del proyecto Semilla Número 160325034. Jaime González agradece el apoyo financiero del proyecto dirigido por la Universidad de Tarapacá, UTA-MECESUP. De igual forma, agradecemos los comentarios y sugerencias de los árbitros anónimos de EURE que sirvieron para mejorar el manuscrito preliminar. Ciertamente, los errores u omisiones son de nuestra completa responsabilidad. Correspondencia: Universidad Diego Portales, Ejército 333, Santiago, Chile. Mauricio Morales. Teléfono: 6768445. E-mail: mauricio.morales@gmail.com | Jaime González.E-mail: jaime-gonzalez@prof.udp.cl 


\section{Presentación}

Existe una amplia literatura sobre la conducta electoral de los chilenos en elecciones presidenciales y parlamentarias (Altman, 2004; López, 2004; Morales, 2008; Navia, 2007, entre otros), al igual que sobre las características del sistema de partidos y los efectos del sistema electoral binominal (Valenzuela, 1995; Scully, 1992; Valenzuela y Scully, 1997; Magar et al., 1998; Siavelis, 2000; Torcal y Mainwaring, 2003; Navia, 2005; Huneeus, 2006, entre otros). Sin embargo, no se ha profundizado en la conducta electoral de grupos específicos que, a pesar de ser minoritarios, permiten una comprensión más acabada del proceso político chileno. En este trabajo analizamos a los grupos indígenas. Si bien consideramos una serie de tiempo que abarca todo el período de la nueva democracia (desde 1989), nos concentramos en la última elección presidencial de 2009/2010. Recurrimos a la información de la encuesta CASEN de 2006 para calcular el porcentaje de población indígena por comuna y de la encuesta de la Universidad Diego Portales que incluye una pregunta sobre adscripción étnica. Los resultados electorales por comuna, en tanto, son extraídos del sitio oficial del Ministerio del Interior (www.elecciones.gov.cl).

La pregunta de investigación pasa por identificar el patrón de votación en las comunas que concentran población indígena. De acuerdo a los datos de la encuesta CASEN, las regiones con mayor concentración son las de Arica y Parinacota (con significativa presencia aymara) y la región de La Araucanía (con predominio mapuche). Como el nuevo trazado regional no tiene implicancias electorales, agrupamos las regiones de Arica y Parinacota junto a la de Tarapacá (Primera Región). Igual cosa hacemos con la Décima Región, sumando la Región de Los Ríos y la Región de Los Lagos. Esto facilita la comparación con elecciones previas al considerar en el análisis al mismo territorio.

Lo anterior forma parte central de nuestra propuesta. No considerar el efecto del territorio sobre los resultados electorales conduce a interpretaciones erróneas o insuficientes. Así, la relación entre porcentaje de población indígena y votación por candidatos de derecha es positiva. No obstante, al controlar por región los resultados varían sustantivamente. El comportamiento es muy distinto al comparar la Primera, Novena y Décima regiones. Mientras en la Primera la relación entre el porcentaje de población indígena y el voto por Sebastián Piñera es positiva, en la Novena dicha relación es cercana a cero, y en la Décima es negativa. En otras palabras, en la Primera Región Piñera obtuvo un mejor desempeño en las comunas con mayor concentración de población indígena en comparación al resto de las comunas de la misma región. En la Novena, tanto las comunas de alto como de bajo porcentaje de población indígena votaron de manera más o menos similar al candidato de derecha en la segunda vuelta de $2010^{1}$, mientras que en la Décima fueron las comunas con mayor concentración indígena las que menos votaron por Piñera. De igual forma, los apoyos hacia Piñera se incrementan sustantivamente en las comunas con mayor porción de población indígena y que, además, presentan altos porcentajes de población rural.

Para un análisis sobre las características socioeconómicas de la Novena Región, ver Cerda (2009). 
Sugerimos como hipótesis que las diferencias electorales entre aymaras y mapuches se explican por el tipo de organización sociopolítica. La mayor verticalidad histórica de los aymara puede dar cuenta de su tendencia hacia partidos y candidatos de derecha desde el plebiscito de 1988, a diferencia de los mapuches, donde dicha organización está más descentralizada. Adicionalmente, las comunas de concentración aymara están territorialmente más alejadas de los principales centros urbanos, lo que contrasta con la realidad mapuche, cuya votación se asemeja a la de las grandes ciudades de la Novena Región. La evidencia indica que las comunas que concentran población indígena muestran un comportamiento electoral más diferenciado mientras más lejos se encuentran de los centros urbanos. Como hipótesis secundaria y colocando el tema en perspectiva comparada, planteamos que el rol de los partidos chilenos ha sido determinante en la integración política de estas poblaciones, evitando la emergencia de partidos indígenas poderosos, lo que contrasta con otros países de la región como Ecuador o Bolivia. Es decir, y tal como lo afirman nuestros informantes calificados, los partidos tradicionales han obstaculizado la institucionalización del movimiento indígena en un partido político.

Este trabajo no sólo entrega pistas en torno al análisis del voto indígena, sino que también sugiere algunas rutas metodológicas. El acento está puesto en la necesidad de incluir al territorio como una variable explicativa de los resultados electorales. Esto también tiene una fundamentación teórica desde un enfoque que si bien escapa al planteamiento politológico de la conducta electoral es muy útil para comprender los resultados. Siguiendo el trabajo compilado por Hidalgo, De Mattos y Arenas (2009), el proceso de urbanización ha alcanzado a ciudades de tamaño medio, que parecen comportarse de manera similar a las comunas más grandes. De esta forma, la ruralidad, que está en torno al $13 \%$ según el último censo de 2002, se recluye a comunas pequeñas. Por tanto, podría esperarse que la conducta electoral varíe en función no sólo del porcentaje de población indígena, sino que también del porcentaje de población rural por comuna considerando la actividad productiva de su población.

Utilizamos información comunal junto a datos de encuestas de opinión y entrevistas a informantes clave. Esta estrategia metodológica contribuye a evitar algunos problemas de falacia ecológica (Ver King et al., 2000). Es decir, realizar inferencias descriptivas o causales de una unidad de análisis a otra. Técnicamente nos basamos, en una primera etapa, en el análisis estadístico. De acuerdo a los datos disponibles implementamos modelaciones lineales y logísticas. Para graficar algunos resultados utilizamos simulaciones estadísticas con el paquete zelig de R (Kosuke et al., 2007). Complementamos este análisis con información directa de entrevistas a algunos informantes clave. Estamos conscientes de las limitaciones que tiene el manejo de algunos de nuestros datos y de los problemas de falacia ecológica o de relaciones espurias que hemos mencionado. Precisamente para corregir este tipo de dificultades es que ampliamos la utilización de los métodos y técnicas más comunes en la realización de este tipo de estudios. Mientras la estadística nos sirve para mapear la votación de la derecha y relacionarla con la población indígena, la historia y las entrevistas son útiles para avanzar en los mecanismos causales que los modelos estadísticos no son capaces de capturar. 
Una limitación corresponde a la naturaleza de los datos disponibles. Si bien el voto se analiza mediante resultados electorales por comuna, esto no desconoce los procesos migratorios. Por ejemplo, si bien la comuna de General Lagos tiene un $99,4 \%$ de población aymara, esto no quiere decir que la población de esta etnia se concentre exclusivamente en este tipo de comunas. Tal como señala Gundermann (2001 y 2003), la población aymara ha migrado sistemáticamente hacia centros urbanos como Arica, Iquique y Antofagasta. Sin embargo, no tenemos certeza de que efectivamente voten en esos centros urbanos, existiendo la posibilidad de que lo sigan haciendo en sus comunas de origen. Esta limitación, si bien disminuye el poder inferencial de los datos, no anula las conclusiones que sobre ellos se formulan.

El artículo se divide en tres secciones. La primera describe los principales enfoques teóricos de la conducta electoral desde la Ciencia Política, complementándose con visiones desde la antropología y la historia. La segunda sección muestra un panorama general de América Latina respecto a la relación entre fraccionalización étnica y la estabilidad de los sistemas de partidos, punto central para colocar el tema en perspectiva comparada. La tercera parte, en tanto, está destinada al análisis de datos. Acá se enfatiza en la necesidad de incluir al territorio y los niveles de urbanización como variables explicativas de los resultados electorales, sosteniéndose que de no hacerlo es posible arribar a relaciones espurias. El artículo cierra con los testimonios de algunos informantes calificados que no sólo ayudan a responder la pregunta de investigación, sino que también contribuyen a una elaboración teórica respecto a los factores que explican la inexistencia de partidos indígenas en Chile.

\section{Enfoques teóricos sobre la conducta electoral}

Hay dos grandes enfoques teóricos sobre la conducta electoral. Por un lado, está la Escuela de Columbia que, a mediados de los 40 s y bajo la conducción de Paul Lazarsfeld, concluyó que los determinantes del voto se encontraban en los grupos de pertenencia de cada individuo. Así, sugería la existencia de tendencias electorales asociadas a religión, ingresos y, ciertamente, etnia (Lazarsfeld et al., 1944). Es en este contexto en que surge, por ejemplo, el voto de clase. López (2004) y López y Morales (2005) han aplicado parte de estos planteamientos para el caso de Chile. Una de sus conclusiones centrales ha ido en la línea de desmitificar el voto de clase. Si bien en la democracia pre 1973 el ingreso de los electores iba asociado a su intención de voto, la nueva democracia trae interpretaciones un tanto más complejas. Siguiendo a Gil (1969), Faúndez (1992) y Valenzuela (2003) el voto de la izquierda en la democracia pre 1973 estaba anclado en las zonas populares con predominio del mundo obrero. El voto de la derecha, en tanto, se recluía en los sectores de mayor ingreso y preferentemente rural. En la nueva democracia, en tanto, este panorama cambia. La lucha electoral de la Unión Demócrata Independiente (UDI) en los sectores populares basada en una competencia directa con el Partido Comunista (PC), le dio triunfos en zonas urbanas tradicionalmente de centro-izquierda (Morales y Bugueño, 2001; Soto, 2001; Joignant y Navia, 2003). 
Esto debilitó la vigencia del voto de clase en Chile. El análisis de Altman (2004) así lo confirma. La derecha vota mejor en las comunas de alto y bajo Índice de Desarrollo Humano (IDH), mientras que la Concertación lo hace en las comunas de IDH medio. La tesis de Altman (2004) también se sostiene al considerar elecciones locales de concejales (Morales, 2009).

El segundo enfoque corresponde a la Escuela de Michigan. Si Columbia es conocido como el enfoque sociológico del voto, Michigan es conocido como el enfoque sicológico. Los estudios dirigidos por Angus Campbell en las décadas del 50 y 60 sugerían que el voto se explicaba por la adhesión afectiva hacia los partidos fruto de la socialización familiar (Campbell et al, 1960). Así, se produce la transmisión intergeneracional del voto. Es decir, el traspaso de las preferencias electorales de padre o madre hacia los hijos (Ver Dowse y Hughes, 1971; Percheron y Jennings, 1981). De este modo, lo que a la larga se produce es la estabilización de las preferencias electorales y la sobrevivencia de los sistemas de partidos. Las versiones más actualizadas del modelo de Michigan sugieren que, si bien la socialización es central para las predisposiciones políticas, también hay componentes de corto plazo que explican la intención de voto (Miller y Shanks, 1996). Acá aparecen las percepciones de la economía y de los atributos de los candidatos. Estas variables estaban presentes en el modelo originario de Michigan, pero con bajo protagonismo teórico (Lewis-Beck et al., 2008)

Hay un enlace más o menos significativo entre estos enfoques y una teoría central en la formación de los sistemas de partidos. Lipset y Rokkan (1967), seguidos luego por Bartolini y Mair (1990), explicaron la estabilidad de los sistemas de partidos de Europa Occidental de acuerdo a la vigencia de clivajes sociopolíticos que se extendían desde las tensiones iglesia-mercado, centro-periferia y clases sociales. Como estos clivajes permanecen en el tiempo y los partidos tratan de posicionarse en cada una de las fisuras, entonces el resultado esperado será la estabilidad de ese sistema. De acuerdo a este enfoque, Scully (1992) explica las continuidades y cambios en el sistema de partidos en Chile².

Esta somera descripción de los modelos de conducta electoral es útil para entender nuestros resultados. Para Columbia, el hecho de pertenecer a alguna etnia es lo que explica la conducta electoral, mientras que para Michigan se requiere de una socialización familiar específica de esa etnia en función de algún partido o tendencia.

\section{La identificación política desde la antropología y la historia}

Desde la antropología el tratamiento de la identificación política y de la identificación partidaria se sustenta en el concepto de identidad política. Por un lado, hay un cuerpo de literatura que aborda el concepto como una propiedad estable (Van Kessel, 1980;

2 Estos modelos de la conducta electoral fueron complementados por visiones teóricas asociadas al voto económico (Fiorina, 1981; Lewis-Beck, 1988; Grofman, 1995; Lewis-Beck y Stegmaier, 2000). Supuestamente, los electores reaccionan a determinantes de corto plazo, tales como las variaciones en la inflación o en el ingreso. Pero también hay coyunturas políticas que pueden explicar los cambios en la conducta electoral. Ejemplo de ello fueron las elecciones presidenciales en España en 2004. Se esperaba un triunfo más o menos holgado del Partido Popular. Sin embargo, los atentados terroristas y la errática reacción del gobierno revirtieron el resultado, saliendo triunfante el candidato del socialismo. 
Zárate, 1993; Smith, 1998 y 1999; González, 2000). Por otro, existen autores que ven a la identidad política como un concepto dinámico y susceptible de cambio a partir de relaciones económicas, organizaciones sociales y estructuras de poder (Wolf, 1987; Vázquez León, 1992; Favre, 1996; Trejo, 2000; González, 2006; Bengoa, 2007; Sen, 2008). Existe una diferencia sustantiva en el tratamiento de la identidad política desde ambos enfoques. Mientras para los primeros la identidad política es inmutable, para los segundos es una construcción en permanente transformación.

Desde la historia, en tanto, el comportamiento político de los agentes indígenas está lejos de ser estático. En tiempos precolombinos, la población amerindia conoció las más diversas organizaciones políticas, oscilando desde estados agrarios y despóticos (Mesoamérica y los Andes Centrales), a comunidades tribales horizontales, sedentarias y nómades (Lameiras, 1985; Palerm, 2007; Murra, 1980; Hidalgo, 1972; León, 1989). Bajo el régimen colonial español se redibujó la estructura de poder. De sociedades agrarias de diverso tipo se transitó gradualmente a una sociedad capitalista. Esto produjo un cambio en la relación patrón-cliente. Desde relaciones clientelares del período precolombino caracterizadas por una estructura plenamente centralizada (por ejemplo, el caso andino entre inca y curaca), se avanzó hacia una relación clientelar entre el colono y el colonizado (encomendero-indio) caracterizada por mayores cuotas de descentralización. Tal descentralización se acentúa al sur del Bío-Bío. Este antecedente puede explicar la naturaleza de los vínculos políticos en el mundo mapuche respecto al aymara. Los mapuches presentan una estructura más horizontal a diferencia de la verticalidad aymara. Uno de los indicadores de verticalidad corresponde a la organización político-parroquial. En el mundo aymara la distribución de cargos de poder se realiza de acuerdo a la estructura jerárquico-local. Mientras tanto, en el mundo mapuche la horizontalidad se refleja en el papel de los jefes de familia (lonkos) para decidir los destinos políticos de la comunidad mayor. Acá la distribución del poder, a diferencia de los aymaras, está más descentralizada. La organización incluye varios lonkos con similares cuotas de poder. En cambio, en el mundo aymara se observa históricamente una figura central y jerárquica (Gundermann, 2001 y 2003a; Assadourian, 1983; Lynch, 1989 y 1993). Este argumento contribuirá a explicar las tendencias electorales de ambos grupos, viéndose reflejadas en las opiniones de nuestros informantes claves.

En los dos siglos de vida política independiente Chile amplió su dominio territorial de norte a sur. Este estiramiento espacio-temporal articuló a diversas poblaciones amerindias tales como los mencionados aymaras, quechuas, atacameños, pero también los mapuches (González, 2000; Bengoa, 2000; Gundermann, 2001; Castro, 2005). Tanto el Norte Grande como la Araucanía formarían parte del proceso de chilenización política, económica y cultural. En el siglo XX, este proceso implicaría insertar a estos grupos al clientelismo político generado por los partidos. Esta integración vertical ligaría la identificación política del ahora ciudadano indígena a su patrón político más cercano (Valenzuela, 1977; Gundermann 2003) ${ }^{3}$. Este hecho no se modificaría sustancialmente bajo el régimen de Pinochet (Gun-

3 La literatura que ha tratado la problemática es bastante amplia. Ver, entre otros, Adams (1978), De la Peña (1995), Wolf (1987). 
dermann, 2003). La municipalización del espacio amerindio y su articulación física con el resto del país establecería un nuevo nexo vertical (Gundermann, 2003). Bajo la redemocratización de las últimas dos décadas el fenómeno mutaría parcialmente. Las dinámicas propias del sistema electoral binominal jerarquizaron a esta población a la política de alianzas de bloque partidario. La nueva democracia pública (Rehren, 2000) explicaría parte de la nueva identificación política indígena. En otras palabras, que la actividad e intervención de los partidos en la estructura de poder interna de estas comunidades evitó la institucionalización del movimiento indígena en un partido político. Este argumento también se sostiene en las opiniones de los informantes claves.

\section{Fraccionalización étnica y estabilidad de los sistemas de partidos en perspectiva comparada}

La literatura comparativa concluye que en aquellos países con mayor fraccionalización étnica se produce una mayor fragmentación partidaria ${ }^{4}$. Esto, porque surgen partidos con intereses específicos en torno a las demandas de los indígenas. Generalmente, la alta fragmentación partidaria va asociada a la inestabilidad política debido a lo difícil que resulta la consolidación de coaliciones de gobierno estables. Adicionalmente y según Madrid (2005), la mayor fraccionalización étnica genera mayores niveles de volatilidad electoral. Es decir, el sistema de partidos se vuelve más inestable. Esto va de la mano con la incapacidad de algunos partidos indígenas para procesar las demandas de sus votantes y la debilidad orgánica de sus colectividades. Comúnmente, los votantes de estos partidos deciden respaldar a otras colectividades que también dicen representar tales intereses. La creación de nuevos partidos, entonces, va incrementando el número de actores en competencia produciendo, en algunos casos pero especialmente en América Latina, mayores niveles de volatilidad. Ecuador, Guatemala, Bolivia y Perú son buenos ejemplos de aquello.

Sin embargo, hay casos que no apoyan la hipótesis. Uno de ellos es México. Si bien su índice de fraccionalización está entre los más altos de la región, su sistema de partidos mantiene niveles de volatilidad incluso por debajo del promedio de América Latina. Una sociedad tan compleja debería ser caldo de cultivo de clivajes étnicos, cuestión que no sucede. Lo que parece explicar tal combinación (alta fraccionalización y moderada volatilidad) se asocia al papel de intermediarios políticos o brokers que sobreponen la estructura partidista a la posible emergencia de partidos indígenas (Adams, 1978; Vázquez León, 1992; De la Peña, 1995; Palerm, 1998; Wolf, 1987). De cualquier forma, la tendencia general de los datos indica una relación más o menos robusta entre ambas variables, pero siempre manteniendo reserva sobre casos concretos como el de México. La Figura 1 muestra el porcentaje de volatilidad promedio

4 El índice de fraccionalización étnica se reporta en la base de datos mundial elaborada por el The Quality of Government Institute. El cálculo consiste en la probabilidad de que dos personas elegidas al azar dentro de un mismo país no pertenezcan al mismo grupo etnolingüístico. Así, el índice combina la dimensión racial y lingüística de los habitantes. Por tanto, aparecerán subestimados aquellos países que cuenten con varias etnias, pero que hablen el mismo idioma. 
de cada país desde 1980 hasta 2006 junto al índice de fraccionalización étnica. En la zona superior derecha del gráfico aparecen, precisamente, los países con mayor porcentaje de fraccionalización étnica y mayor volatilidad. Nos referimos a Perú, Bolivia y Ecuador. En la zona izquierda, en tanto, están los sistemas menos fraccionalizados étnicamente y con menor volatilidad como Chile, Uruguay y Honduras.

\section{FIGURA 1 | Volatilidad electoral y fraccionalización étnica en América Latina}

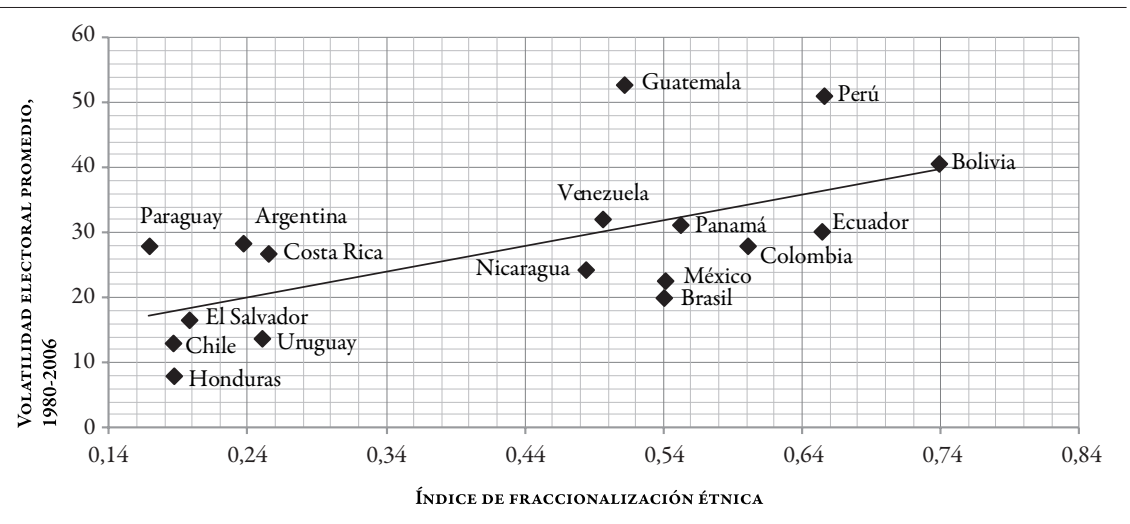

FUENTE ELABORACIÓN PROPIA. PARA VOLATILIDAD SE UTILIZARON LOS DATOS DEL OBSERVATORIO DE PARTIDOS POLÍTICOS DE LA UNIVERSIDAD DE SALAMANCA, HTTP://AMERICO.USAL.ES/OIR/OPAL/. EL ÍNDICE DE FRACCIONALIZACIÓN ÉTNICA FUe EXTRAído DE LA BASE DE DATOS DE The Quality of Government INSTITUTE, HTTP:// WWW.QOG.POL.GU.SE.

A diferencia de América Latina y según Bartolini y Mair (1990), la fraccionalización étnica no va asociada a mayores niveles de volatilidad, al menos en Europa Occidental. Esto, porque los partidos que defienden los intereses de las minorías suelen ser estables y permanentes en el tiempo y con mayor poder de organización. Entonces, si bien la fragmentación aumenta, no genera un efecto sobre los niveles de volatilidad. Esto tiene correlato con el trabajo de Lijphart (1999). Según el autor, la fragmentación partidaria se incrementa en la medida en que aumentan las líneas de división o conflicto entre los partidos políticos. Lo que se produce, en definitiva, es un aumento en las dimensiones de competencia. El eje étnico es uno de ellos. En América Latina, en tanto, generalmente el surgimiento de partidos étnicos va asociado a mayores niveles de volatilidad y a sistemas de partidos inestables (Madrid, 2005).

Otra respuesta es la que elaboran Rice y Lee Van Cott (2006). Para las autoras, el auge de los partidos indígenas en América Latina se explica por diseños institucionales permisivos para la emergencia de estos partidos, reglas electorales que incluyen una alta magnitud de distrito y efectos de difusión o contagio (también denominado "efecto demostración") entre los países, al igual que por condiciones estructurales. Así, los altos niveles de pobreza y la menor fuerza de la identidad de clase en términos de adscripción partidaria explicarían por qué estos partidos pueden llegar a emerger. El efecto del contagio no es menor. Según Rice y Lee Van Cott (2006, p. 714), el éxito del Movimiento Alianza Social Indígena en Colombia 
explicó el surgimiento de partidos indígenas en Bolivia y Ecuador a mediados de los 90. De igual forma, un predictor del desempeño de los partidos indígenas es la magnitud de distrito. Cuando el número de escaños disponibles en cada unidad geográfico-electoral es más alto, aumentan las probabilidades de éxito para estos partidos y para colectividades más pequeñas (Coppedge, 1997; Birnir, 2006).

Un segundo punto a rescatar consiste en que no siempre la mayor fraccionalización étnica equivale a la emergencia de partidos indígenas exitosos. Un caso es Perú. Acá, el movimiento indígena fue satelizado por los partidos de izquierda evitando la emergencia de una agenda étnico-cultural. Algo similar, pero a menor escala, es lo que sucede en Chile. La división étnica tiende a eclipsarse producto de la presencia de partidos de izquierda (Rice y Lee Van Cott, 2006, p. 715). Esto es lo que impide que en algunos países aparezcan partidos indígenas fuertes. Donde los partidos más tradicionales de izquierda se ven debilitados y la organización indígena está más institucionalizada, la emergencia de partidos étnicos se hace más viable.

Most of the new indigenous parties are deeply rooted in dense networks of social organizations that channel the interests and preferences of indigenous peoples to political party leaders, who are relatively more responsive to them than traditional political party elites (Rice y Lee Van Cott, 2006, p. 710).

\section{Análisis de datos}

El Cuadro 1 muestra el grado de correlación entre la votación por candidatos presidenciales de derecha y el porcentaje de población indígena por comuna. Esta última información se extrajo de la Encuesta Casen 2006. La relación también fue controlada con los datos del Censo 2002 y los resultados son muy similares. No disponemos de información sobre porcentaje de población indígena por comuna en los 90 , por lo que los resultados para esta década deben ser tomados con precaución.

CUADRO 1 | Matriz de correlaciones entre el porcentaje de votación para candidatos presidenciales de derecha y el porcentaje de población indígena*

\begin{tabular}{lcc}
\hline & Datos Sin Ponderar & Datos ponderados \\
\hline Porcentaje del “Si”, 1988 & 0,364 & 0,229 \\
& $(322)$ & $(7232297)$ \\
\hline Porcentaje de Büchi, Presidencial 1989 & 0,228 & $-0,023$ \\
\hline Porcentaje de Lavín, Presidencial 1999 & $(322)$ & $(7158727)$ \\
\hline Porcentaje de Piñera, Presidencial 2005 & 0,316 & 0,138 \\
\hline Porcentaje de Piñera, Presidencial 2009 & $(329)$ & $(7326753)$ \\
\hline
\end{tabular}

${ }^{*}$ En cada casilla figura el coeficiente beta no estandarizado y entre paréntesis el número de casos. En los datos sin ponderar figura el número de comunas, y en los datos ponderados el número de votos emitidos en cada elección.

FUENTE ELABORACIÓN PROPIA CON DATOS DE WWW.ELECCIONES.GOV.CL Y WWW.CASEN.CL 
A pesar de tales limitaciones, se observa sistemáticamente una correlación directa entre el porcentaje de población indígena y el desempeño electoral de los candidatos de derecha incluyendo la opción "Sí" en el plebiscito de 1988. El coeficiente baja al ponderar los datos según tamaño comunal e incluso es levemente negativo al considerar las presidenciales de 1989. La ponderación se realiza dado que Chile tiene un desbalance evidente en los tamaños comunales. Por ejemplo, mientras en La Florida votaron válidamente 145.421 personas en la segunda vuelta de la presidencial 2009/2010, en Tortel lo hicieron 282. Lo que hacemos con la ponderación consiste en descomponer las unidades territoriales pesándolas de acuerdo a su tamaño real y no contándolas como si fuesen de igual magnitud. Es muy distinto obtener un 10\% de los votos en La Florida que un 10\% en Tortel. Entonces, mediante el proceso de ponderación las comunas son pesadas de acuerdo a su tamaño poblacional o al número de votos emitidos en cada elección. Como el coeficiente de correlación baja, se puede inferir que si bien la relación entre porcentaje de población indígena y voto por la derecha es positiva, parece ser más fuerte en las comunas pequeñas en comparación a las comunas más grandes. En otras palabras y considerando la distribución de la población indígena, la relación sería más robusta en las comunas de la Primera Región respecto a la Novena.

Lo que podría explicar las diferencias entre la Primera y Novena regiones corresponde a la histórica organización jerárquica y autoritaria de la zona andina en relación el tipo de población indígena. Sus antecedentes se encuentran en tiempos precolombinos. Bajo el régimen colonial esta situación no se modificó sustantivamente. Bajo la República peruana se mantuvo como vínculo neocolonial, y bajo el Estado nacional chileno la vinculación fue vertical y durante un tiempo con altos grados de hostilidad. Sería en el siglo XX que el sistema político nacional integraría verticalmente a esta población. Primero con los partidos y posteriormente bajo el régimen de Pinochet. La municipalización del espacio andino y su democratización bajo la Democracia Pública no modificó sustancialmente la política jerárquica y autoritaria andina.

Lo anterior es respaldado por la Figura 2. Acá se muestra la distribución de la población indígena según región y el porcentaje de Piñera en la segunda vuelta de 2010. Las regiones predominantemente indígenas son, precisamente, la Primera y Novena. Piñera tuvo un desempeño destacado en ambas regiones. En la Primera, como hemos dicho, hay significativa presencia de población aymara, cuyos miembros han sido históricamente agricultores, ganaderos y comerciantes desde tiempos precolombinos. En la Novena predomina la población mapuche. Pasaron de ser agricultores en el siglo XVI para transformarse en cazadores pampinos en el siglo XVII. En el siglo XVIII serían maloqueros y conchavadores 5 (León, 1991), para terminar siendo ganaderos en el siglo XIX y agricultores menores en el siglo XX.

5 El término maloquero viene de "maloca", que significa ataque fronterizo. Es equivalente a la campeada española. Es decir, a la actividad bélica asociada al ingreso militar a un territorio enemigo cuyo principal objetivo sería el botín de guerra (mujeres, ganado y niños). El conchavador, en cambio, viene de "conchavo" que significa comercio. La maloca y el conchavo fueron dos actividades asociadas. Se entenderá que el comercio se activaba principalmente por el botín de guerra. 
FIgURA 2 | Desempeño electoral de Piñera por región según porcentaje de población indígena.

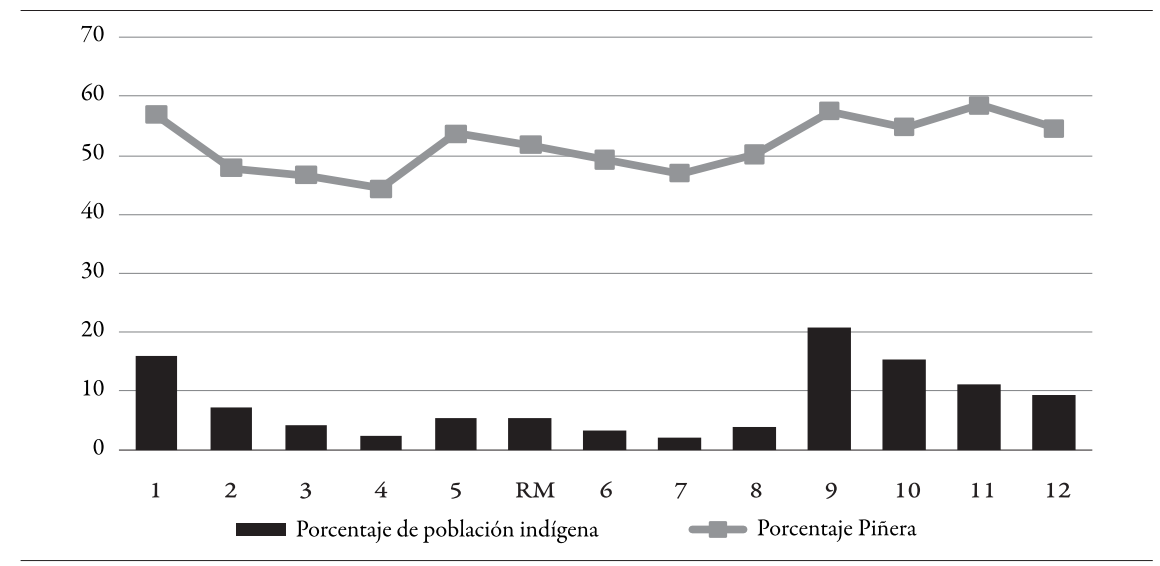

FUENTE ELABORACIÓN PROPIA CON DATOS DE WWW.ELECCIONES.GOV.CL Y WWW.CASEN.CL

Estos primeros resultados hacen pensar en una relación directa entre porcentaje de población indígena y voto por Piñera. Las regiones Primera y Novena son las que cuentan con los porcentajes más altos de ambas variables (población indígena y voto por Piñera). Sin embargo, una conclusión de este tipo descuida las variaciones que se producen dentro de cada región y, en tal sentido, la inferencia podría ser falaz. Por tanto, el análisis se enfoca no sólo en las variaciones interregionales, sino que también intrarregionales. Para aproximarnos, construimos un gráfico que incluye a las comunas que tienen sobre un $40 \%$ de población indígena. Esto podría ser interpretado como un sesgo de selección de casos, pero sólo lo mostramos para identificar las comunas donde la relación parece ser más evidente. La Figura 3, por tanto, correlaciona el porcentaje de población indígena (por sobre el 40\%) y el voto por Piñera. En la zona superior derecha aparecen comunas de la Primera Región como Colchane y Camiña. El porcentaje de población indígena en esas comunas bordea el 95\%. Son comunas pequeñas y rurales, pero donde Piñera obtuvo alrededor del $85 \%$ de los votos y los partidos de derecha han sido históricamente fuertes. Más atrás, hay algunas comunas de la Novena Región como Melipeuco o Curarrehue donde Piñera bordeó el 70\% de los votos y donde también los partidos de derecha han sido históricamente hegemónicos. No obstante, hay algunas comunas con alta concentración de población indígena también de la Novena Región donde la votación por Piñera estuvo muy por debajo de estos porcentajes, como sucedió en Saavedra, Galvarino y Freire. Si bien en estas dos últimas logró la mayoría absoluta, la elección fue mucho más reñida que en Melipeuco o Curarrehue. En el resto de las comunas de la Primera Región con alta concentración de población indígena fuera de Colchane y Camiña, Piñera no bajó del 54\%. 
FIGURA 3 | Porcentaje de votación por Piñera según población indígena por comuna por sobre el $40 \%$

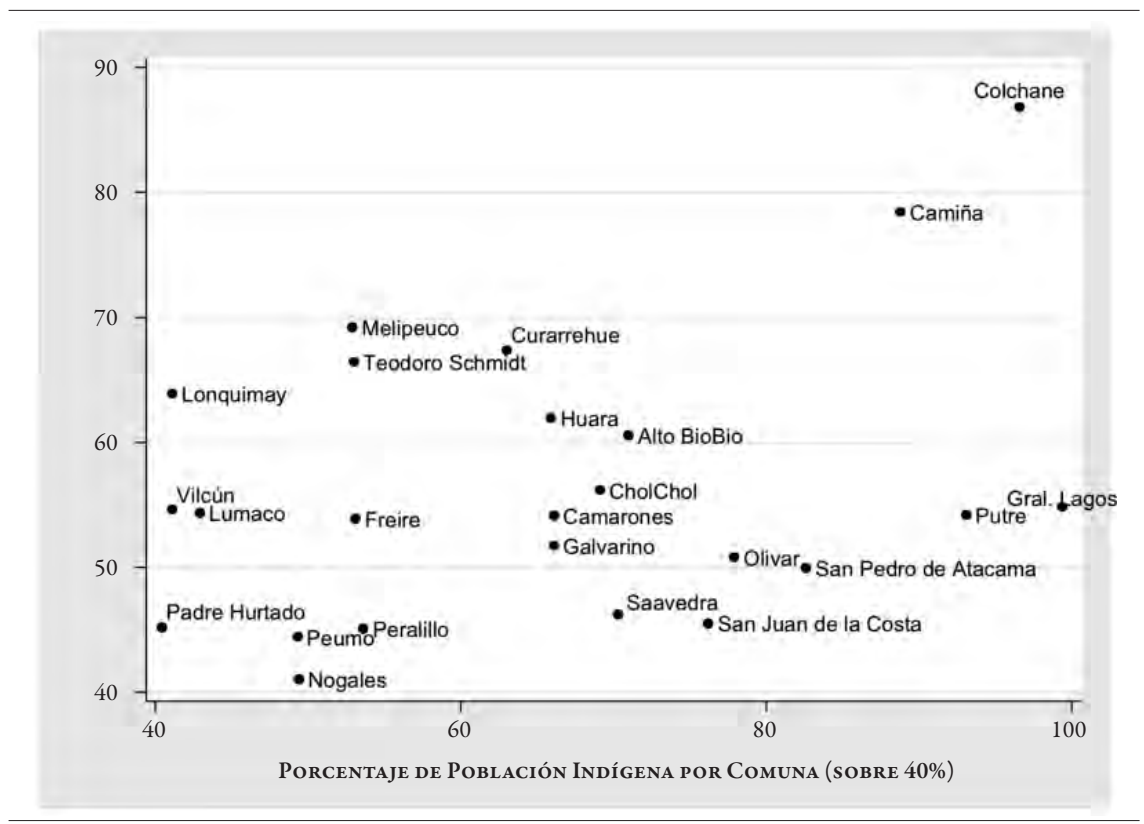

FUENTE ELABORACIÓN PROPIA CON DATOS DE WWW.ELECCIONES.GOV.CL Y WWW.CASEN.CL

Entonces, hay variaciones intraregionales muy significativas. El hecho de que la comuna concentre población indígena al menos en la Novena Región no es sinónimo de que la derecha obtenga amplia ventaja sobre la Concertación, a diferencia de lo que sucede en las comunas con predominio indígena de la Primera Región, donde el voto por la derecha es mayoritario e históricamente estable. La Figura 4 muestra la relación entre población indígena y voto por Piñera en todo el país y luego en las regiones Primera, Novena y Décima. Como puede apreciarse, la relación es positiva pero débil en el total nacional, con un coeficiente de correlación de 0.31 . En la Primera el coeficiente es de 0.4 , cercano a cero en la Novena (0.05) y negativo en la Décima (-0.25) considerando datos sin ponderar y con todas las comunas de cada región.

La relación entre porcentaje de indígenas por comuna y voto por la derecha también debe ser controlada según los niveles de urbanización. Como mencionábamos más arriba y de acuerdo al trabajo de Hidalgo, De Mattos y Arenas (2009), la situación territorial de Chile apunta hacia una reducción de la ruralidad, lo que no sólo se aplica para las grandes ciudades, sino que también para las de tamaño medio. En función de este antecedente, entonces, se podría presumir un comportamiento electoral distinto en aquellas comunas con alto porcentaje de ruralidad. La correlación entre ruralidad y porcentaje de indígenas por comuna es de 0.33 , un coeficiente más bajo de lo que podría esperarse. No obstante, las comunas que concentran mayor porcentaje de indígenas son predominantemente rurales. En otras palabras, y aunque parezca muy obvio, 
no todas las comunas rurales presentan altos porcentajes de indígenas, pero las comunas con concentración indígena son predominantemente rurales. Entre ellas destaca General Lagos, Colchane, Putre, San Juan de la Costa, Saavedra, entre otras. La diferencia central entre las comunas de la Primera y Novena regiones que concentran población indígena corresponde a las distancias con los centros urbanos. Así, por ejemplo, la distancia entre Colchane y Arica es de 394 kilómetros, mientras que entre Camiña y Arica es de 256 kilómetros. Para ambas, la distancia se reduce con Iquique, pero de todas formas es superior a lo que pasa en la Novena Región. Melipeuco está a 94 kilómetros de Temuco, mientras que Saavedra está a 86 kilómetros. Nuevamente, el factor territorial muestra incidencia. Al parecer, las comunas más distantes de los centros urbanos mantienen comportamientos electorales muy particulares. Esto puede obedecer a su falta de interacción inmediata con estos centros urbanos de mayor envergadura.

FIGURA 4 | Relación entre el voto por S. Piñera y porcentaje de población indígena en el total nacional, Primera, Novena y Décima regiones
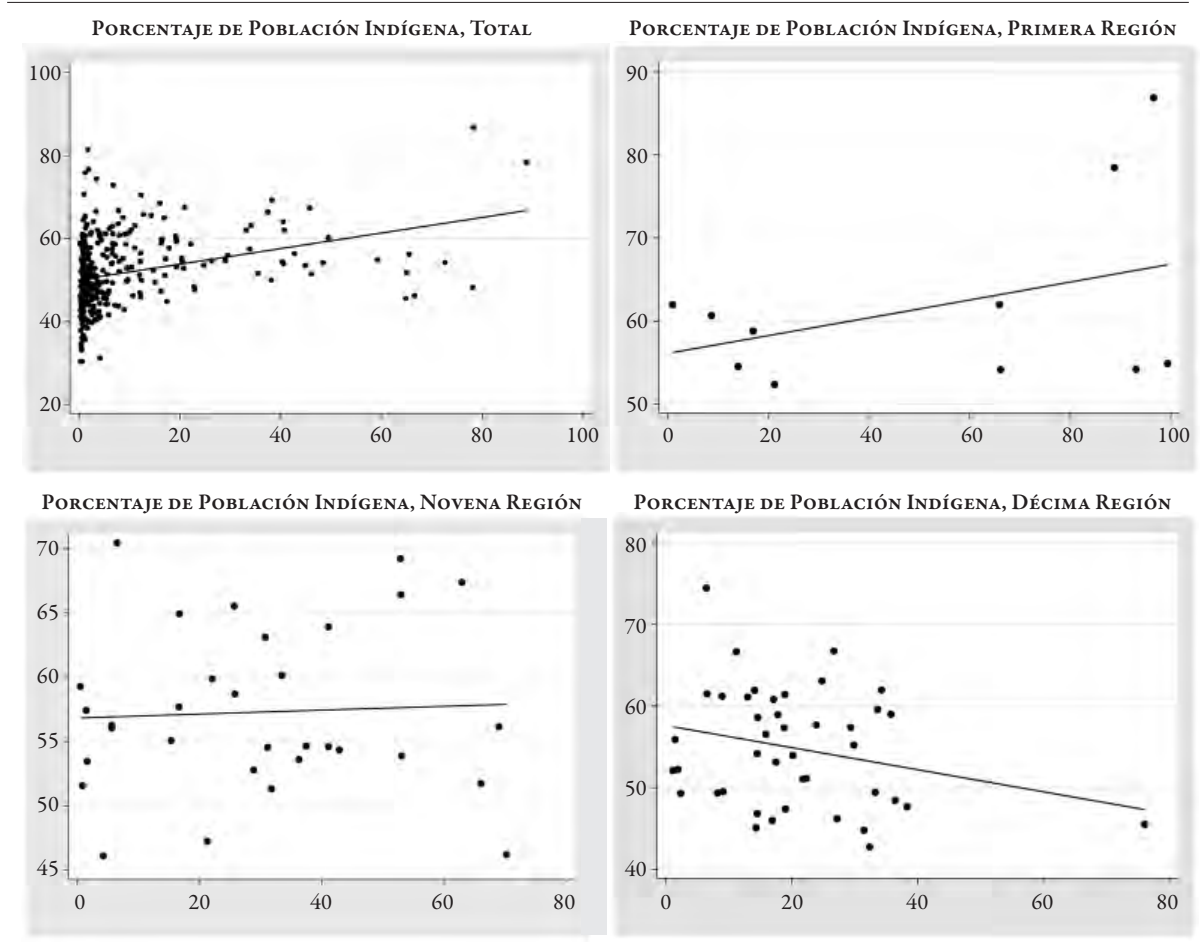

FUENTE ELABORACIÓN PROPIA CON DATOS DE WWW.ELECCIONES.GOV.CL Y WWW.CASEN.CL

Para analizar más detalladamente lo anterior, dividimos las comunas considerando aquellas que están por sobre y por debajo del $50 \%$ de población rural. Para ambos grupos se correlaciona nuevamente la votación de Piñera con el porcentaje de indígenas. El resultado arroja una relación mucho más fuerte en aquellas comunas con mayor 
porcentaje de población rural. El coeficiente de correlación es de 0.44 , mientras que para el grupo de comunas que están por debajo del 50\% de ruralidad dicho coeficiente es de 0.16. Es decir, Piñera logró mejores resultados en comunas con alta concentración indígena y con fuerte predominio rural. Por ejemplo, en Colchane Piñera obtuvo un $86,81 \%$ y en Camiña un $78,4 \%$. En ambos casos la ruralidad llega al $100 \%$. Pero estos resultados no son atribuibles exclusivamente a la candidatura de Piñera. Estas comunas tienen una tradición de voto por candidatos de derecha. De hecho, en el plebiscito de 1988 la opción "Sí" obtuvo un 81\% y 73\% respectivamente. Acá la concentración de población aymara es altísima, con 96,6\% en Colchane y $88,8 \%$ en Camiña.

Esta primera parte del trabajo arriba a una conclusión preliminar. Si bien se observa cierto grado de relación entre el porcentaje de población indígena y el voto por Piñera y por la derecha en general, todo apunta a que esta relación es más fuerte en comunas de baja densidad de habitantes y con bajos niveles de urbanización. Los casos más sobresalientes son algunas comunas de la Primera Región (Colchane y Camiña), pero también destacan otras localidades también pequeñas de la Novena Región donde Piñera obtuvo porcentajes por sobre el promedio nacional, como Melipeuco, Curarrehue y Teodoro Schmidt. Esto indica que, para algunas comunas, el hecho de concentrar población indígena, ser predominantemente rurales y presentar una baja densidad de habitantes, se transforma en un fuerte predictor del voto hacia candidatos de derecha. La relación parece ser más clara en la Primera Región, pero eso se explica, básicamente, por las características políticas y sociodemográficas de Colchane y Camiña. En la Novena se da una mayor variación de estas condiciones, existiendo comunas similares en términos socioeconómicos y sociodemográficos, pero con algunas diferencias políticas. Es lo que sucede, por ejemplo, con Saavedra y Galvarino donde el desempeño de Piñera fue inferior al resto de las comunas con alta concentración indígena.

Otro punto a considerar pasa por la comparación con el resto de las comunas dentro de la misma región. Es decir, con aquellas que tienen menor o nulo porcentaje de población indígena. En la Primera Región las comunas con alta concentración de población indígena prefieren en mayor medida candidatos de derecha respecto a las comunas con menor concentración indígena. Por ejemplo, si en Huara (con 66\% de población indígena) Piñera obtuvo casi el 62\%, en Arica (con 14,7\% de población indígena) alcanzó el $52 \%$. En la Novena, en cambio, la preferencia por candidatos de derecha es más o menos similar en comunas con alta y baja concentración de población indígena. Por ejemplo, si en Lonquimay (con 41,1\% de población indígena) o Cholchol (con 69\% de población indígena) Piñera alcanzó el 64\% y 56\% respectivamente, en Pucón (con 12\% de población indígena) obtuvo más del $70 \%$ y en Cunco (con 20\% de población indígena) superó el 60\%. En consecuencia, mientras en la Primera Región las comunas con mayor porcentaje de población indígena muestran una tendencia clara a favor de candidatos de derecha, no sucede lo mismo con las comunas de esa misma región pero que presentan bajos porcentajes de indígenas. En la Novena Región, en cambio, las comunas con altos y bajos porcentajes de población indígena votan de manera más o menos similar. 
Estos resultados sólo entregan una panorámica general y son útiles para mapear la votación del actual Presidente en función del porcentaje de población indígena. En la siguiente sección analizamos con mayor detalle el vínculo entre ambas variables sobre la base de un análisis inferencial.

\section{Los modelos}

A continuación mostramos tres modelos que miden el efecto del porcentaje de población étnica sobre la votación de Piñera en la segunda vuelta de 2010 (Ver Cuadro 3). Controlamos los modelos incluyendo al Índice de Desarrollo Humano (IDH) que captura dimensiones de pobreza, educación y esperanza de vida. Con esto, controlamos los resultados por las características socioeconómicas de cada comuna. Adicionalmente, existe suficiente evidencia empírica sobre el efecto del IDH en la votación por las coaliciones. Como decíamos más arriba, lo esperado es que la derecha logre mejores resultados en las comunas de IDH alto y bajo. Para corroborar esto, incluimos el IDH y su cuadrática como los dos primeros predictores. El modelo respalda la tesis de Altman (2004), mostrando que, efectivamente, Piñera logró mejor desempeño en comunas muy ricas y también en localidades pobres (el signo del coeficiente de IDH es negativo y su cuadrática positiva). El modelo, además, señala un efecto positivo del porcentaje de población étnica sobre la votación por Piñera. Es decir, a mayor porcentaje de población étnica, mayor voto por Piñera. Sin embargo, este modelo no incluye un factor que controle el efecto de cada región sobre los resultados. Bien pudiera ser que la votación de Piñera obedezca más a un patrón regional que a la existencia de porcentajes significativos de población indígena en algunas comunas. Para revisar esto se construye un modelo con efectos fijos por región (Modelo 2). Acá el porcentaje de población indígena deja de ser un predictor significativo, sugiriendo que el voto por Piñera se explica más por las condiciones de vida que tienen las comunas y por la región a la que pertenecen.

CUADro 2 | Correlaciones entre porcentaje de S. Piñera (segunda vuelta 2010) y porcentaje de población indígena según ruralidad

\begin{tabular}{rc|c}
\hline & $\begin{array}{c}\text { COMUNAS CON 50\% O MÁS DE } \\
\text { POBLACIÓN RURAL }\end{array}$ & $\begin{array}{c}\text { COMUNAS CON MENOS DEL 50\% DE } \\
\text { POBLACIÓN RURAL }\end{array}$ \\
\cline { 2 - 3 } & Porcentaje de población indígena & Porcentaje de población indígena \\
\cline { 2 - 3 } $\begin{array}{r}\text { Porcentaje de S. Piñera, } \\
\text { segunda vuelta 2010 }\end{array}$ & 0.44 & 0.16 \\
\cline { 2 - 3 } & \multicolumn{2}{c}{ Total de comunas } \\
\hline \multicolumn{2}{c}{0.29} \\
\hline
\end{tabular}

FUENTE ELABORACIÓN PROPIA CON DATOS DE WWW.ELECCIONES.GOV.CL Y WWW.CASEN.CL

El Modelo 3 es de carácter multinivel. Cada comuna va asociada a una región y, en tal sentido, el modelo funciona considerando estos dos niveles de análisis. El software R permite calcular lo que se denomina como Inter-Class Correlation (ICC), que indica el porcentaje de varianza explicada atribuible a los grupos que, 
en este caso, corresponden a las regiones. Dicho porcentaje es del $44 \%$. Esto viene a confirmar que, en efecto, el peso regional es significativo a la hora de explicar la votación por Piñera y que el porcentaje de población indígena deja de ser una variable relevante al controlar por territorio. Así, corroboramos que a nivel general la relación entre porcentaje de población indígena y voto por la derecha es débil. Sin embargo, al considerar a cada región como unidad autónoma, las diferencias afloran con mayor claridad, lo que certificamos en el análisis descriptivo anterior comparando las comunas de las regiones Primera y Novena ${ }^{6}$.

CUADRO 3 | Modelos de regresión lineal. La variable dependiente es el porcentaje de votos de S. Piñera en la segunda vuelta de 2010

\begin{tabular}{|c|c|c|c|}
\hline & MODELO 1 & MODELO 2 & MODELO 3 \\
\hline & $\begin{array}{l}\text { MODELO LINEAL } \\
\text { MÚLTIPLE }\end{array}$ & $\begin{array}{l}\text { MODELO LINEAL MÚLTIPLE } \\
\text { CON EFECTOS FIJOS POR } \\
\text { REGIÓN }\end{array}$ & $\begin{array}{l}\text { MODELO LINEAL } \\
\text { MULTINIVEL POR } \\
\text { REGIÓN }\end{array}$ \\
\hline \multirow[t]{2}{*}{ IDH } & -469.407 & -402.815 & -406.973 \\
\hline & $(5.27)^{* *}$ & $(4.88)^{* *}$ & $(4.95)^{* *}$ \\
\hline \multirow[t]{2}{*}{$\mathrm{IDH}^{2}$} & 352.916 & 313.937 & 316.621 \\
\hline & $(5.68)^{* *}$ & $(5.53)^{* *}$ & $(5.59)^{* *}$ \\
\hline \multirow[t]{2}{*}{ Porcentaje de población indígena } & 0.144 & 0.028 & 0.0419 \\
\hline & $(5.97)^{* *}$ & $(1.03)$ & $(1.56)$ \\
\hline \multirow[t]{2}{*}{ Constante } & 204.296 & 178.359 & 179.657 \\
\hline & $(6.40)^{* *}$ & $(5.94)^{* *}$ & $(5.99)^{* *}$ \\
\hline Observaciones & 329 & 329 & 329 \\
\hline $\mathrm{R}^{2}$ & 0.22 & 0.18 & \\
\hline
\end{tabular}

FUENTE ELABORACIÓN PROPIA CON DATOS DE WWW.ELECCIONES.GOV.CL Y WWW.CASEN.CL

Para cerrar, mostramos dos Figuras adicionales (5a y 5b). Tales Figuras simulan el efecto del porcentaje de población indígena sobre el voto por Piñera. Utilizamos el paquete zelig de R para construir dichas simulaciones (Kosuke et al., 2007). El primer gráfico corresponde al Modelo 1. Es decir, la relación general sin controlar por efectos regionales. Claramente, se observa que el incremento del porcentaje de población indígena va asociado a un aumento en el voto de Piñera. Mientras tanto, la segunda gráfica corresponde al modelo que controla por efectos de grupo (región), indicando que ambas variables no se encuentran estrechamente relacionadas.

6 También se construyó un modelo donde se incluye un término de interacción entre porcentaje de población indígena y porcentaje de población rural. Los resultados indican, precisamente, algo que se anunciaba más arriba. Es decir, que Piñera logra mejores resultados en comunas pequeñas, rurales y con alta concentración de población indígena. 
FIGURA 5 | Relación entre el voto por S. Piñera y porcentaje de población indígena en el total nacional, Primera, Novena y Décima regiones
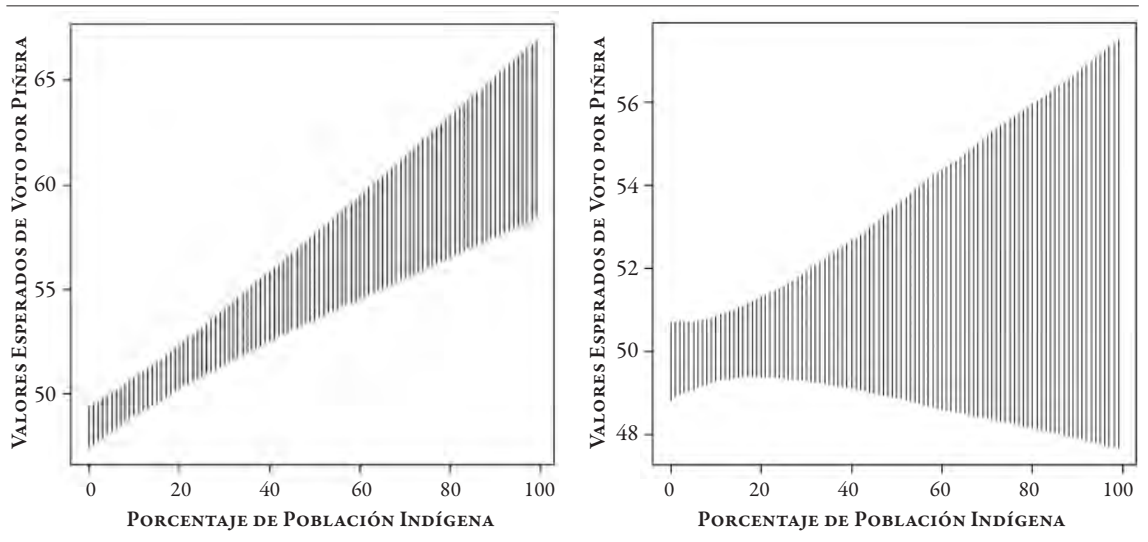

FUENTE ELABORACIÓN PROPIA CON DATOS DE WWW.ELECCIONES.GOV.CL Y WWW.CASEN.CL

La conclusión es más o menos evidente. Un análisis que descuide el efecto regional o las características socioeconómicas de las comunas puede interpretar un impacto lineal del porcentaje de población indígena sobre la votación de la derecha. Un análisis más cuidadoso enfatiza en las variaciones intrarregionales que pueden dar mejores pistas sobre esta relación. Como revisamos más arriba, en la Primera Región la relación es más robusta, perdiéndose en la Novena y siendo inversa en la Décima. Esto nos retrata un comportamiento diferenciado según el tipo de población étnica. La población aymara, en términos de conducta electoral, no puede ni debe tratarse conjuntamente o dentro de un mismo grupo con la población mapuche. Todo indica que tienen comportamientos totalmente diferentes. La historia política aymara, como señalamos, ha sido jerárquica y autoritaria desde tiempos precolombinos. La historia mapuche, en cambio, se caracteriza por una estructura de poder más horizontal. Ahora, sociológicamente los aymaras tienen mayor nivel de ingresos en comparación a la población mapuche, dato que podría contribuir a una explicación algo más robusta de los resultados que acabamos de enunciar. Aunque Colchane exhibe altos porcentajes de hogares pobres considerando la encuesta CASEN 2006, las comunas de la Novena Región con alta concentración indígena presentan niveles de pobreza más altos que las comunas de la Primera Región, destacando Curarrehue, Galvarino y Saavedra.

El análisis no descarta de manera tajante el efecto del porcentaje de población indígena sobre el voto por la derecha. Simplemente, sostiene que dicha relación no es generalizable para todas las comunas del país y que su fijación está en territorios claramente definidos. Por una parte, y como hemos mencionado, algunas comunas de la Primera Región y, por otra, algunas comunas de baja densidad poblacional correspondientes a la Novena Región. 
Para certificar lo anterior recurrimos al análisis de la encuesta ICSO-UDP correspondiente a octubre de 2009. La encuesta formula una pregunta sobre adscripción étnica. Estamos conscientes respecto a las limitaciones del instrumento y que, a lo mejor, la pregunta no sea la más adecuada. Sin embargo, es el dato más actualizado del que disponemos en materia de opinión pública. La pregunta que se formula es la siguiente: "Una forma de entender la nación chilena es a través de la mezcla entre lo indígena y lo español. Si tuviera que escoger entre ambos orígenes, ¿con cuál se identifica más Ud.?”. Las alternativas son indígena (que alcanza un 33,4\%), Español (34,2), Ambos (25,5\%), Ninguno (5,6). Para analizar las predisposiciones políticas de estos electores diseñamos un modelo de regresión logit. Comparamos a los autoidentificados como indígenas con el resto de la población. Claramente, el porcentaje de la encuesta sobrestima el volumen de población indígena, pero de todas formas sirve como una aproximación. La variable dependiente es la intención de voto por Piñera en la segunda vuelta.

FIGURA 6 | Relación entre el voto por S. Piñera y porcentaje de población indígena en el total nacional, Primera, Novena y Décima regiones

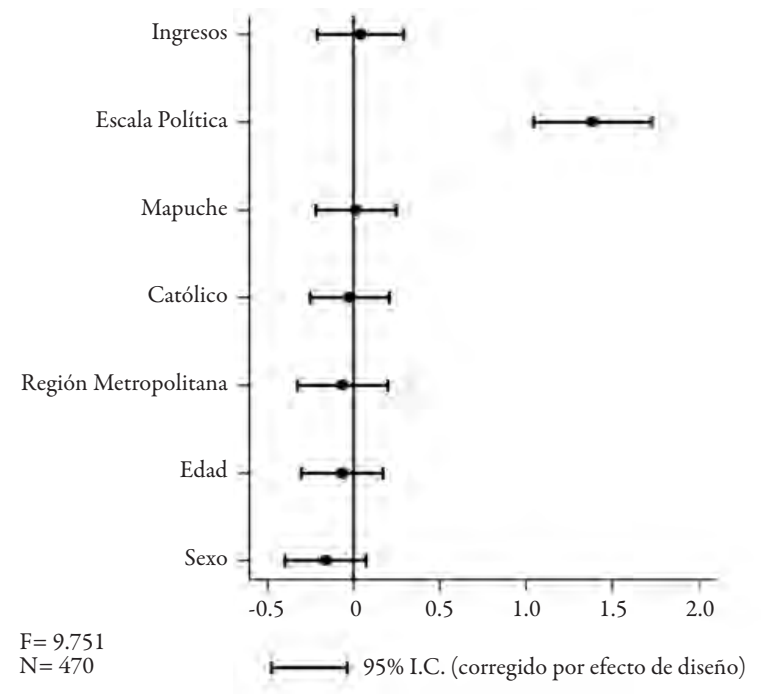

FUENTE BARÓMETROS DE LAS AMÉRICAS POR LAPOP

La Figura 6 muestra los resultados. Cada variable lleva asociada una barra. El punto central de cada barra corresponde al coeficiente de regresión y aparece con sus respectivos intervalos de confianza. Cuando la barra toca el valor "0", implica que el coeficiente no es estadísticamente significativo. Es lo que sucede con la adscripción indígena (mapuche). La única variable significativa a la hora de explicar la votación por Piñera es la escala política. Mientras más de derecha sea el encuestado, mayores probabilidades tiene de votar por el candidato de la Coalición por el Cambio. 
Para complementar este análisis, también hacemos uso de la encuesta del CEP denominada "una radiografía de los mapuches" que se realizó en julio de 2002. Utilizando la misma pregunta de la encuesta CASEN, se advierte que los identificados con alguna etnia tienen predisposiciones políticas similares al resto de la población, al menos en lo que respecta a autoubicación en la escala política izquierda-derecha. Si bien los identificados con etnias aparecen con un apoyo mayor a la Concertación en comparación a la Alianza, en la escala política son más o menos similares. Además, el bajo número de casos que reporta la encuesta no permite realizar inferencias del todo robustas. Sólo alrededor del 8\% declara alguna adscripción étnica. La encuesta UDP, en cambio, reúne un mayor número de encuestados identificados étnicamente en comparación a la del CEP. La gran diferencia entre ambas mediciones se explica por el tipo de pregunta. Mientras en la UDP es sólo un cierto grado de adscripción, la del CEP es más específica, pues mide pertenencia. Así y todo, los resultados van en la línea que hemos venido detallando.

\section{Observación indirecta complementaria}

Para complementar los datos cuantitativos nos apoyamos en entrevistas semidirigidas o semiestructuradas. Si bien existen preguntas predefinidas, no se menoscaba la espontaneidad de los informantes. Se trata de información microscópica de la Primera Región. Como señalamos, acá la relación entre el porcentaje de población indígena y el voto por candidatos de derecha es directa y fuerte. Por tanto, bien vale una explicación desde la misma comunidad, pero, más importante aún, conocer las razones por las que no se ha institucionalizado un movimiento indígena con aspiraciones electorales. Si bien no dudamos de las limitaciones que implica excluir a otros grupos amerindios, resultará útil para una comprensión mayor del voto indígena al menos en este territorio.

Nos basamos en tres testimonios de informantes claves de un total de 14 entrevistas. La selección se realiza considerando su participación en el Pacha Aru ${ }^{7}$, la organización étnica con mayor peso histórico de la Primera Región. Se trata de actores políticos elitarios. A diferencia del registro de encuestas, la observación indirecta levantó información ligada a la cúpula política aymara. Debido a la necesidad de proteger su verdadera identidad, se optó por modificar sus nombres de pila por seudónimos. Los apellidos, orígenes domiciliarios y actividades actuales se omiten por los mismos motivos. El elemento en común de estos testimonios radica en eslabonar la identidad política aymara al poder de los partidos. El argumento gira en torno a un punto que mencionábamos más arriba. Siguiendo a Rice y Lee Van Cott (2006), la existencia de partidos tradicionales generalmente evita la emergencia de partidos indígenas. Cuando estos partidos tradicionales satelizan la discusión étnica, son capaces de fragmentar los movimientos indígenas evitando su institucionalización en un partido. Chile es ejemplo de ello.

7 Corresponde a la principal organización étnica aymara articulada en el Norte Grande en los años 80. Se entiende por organización étnica un tipo de asociación política muy próxima a lo que se entiende por partido con la diferencia de que sus representantes no se presentan a cargos de elección popular. Para profundizar en esto, ver Vázquez León, 1992. 
Para el caso de Alfredo, el predominio de los partidos en la identificación política aymara es de larga data. En su ejercicio como agente político del Pacha Aru sostuvo que el fenómeno tiene sus antecedentes al finalizar la década de los ochenta. Mientras el régimen de Pinochet entraba en crisis, los partidos de la actual Concertación intentaron infiltrar al movimiento indígena trayendo como resultado un debilitamiento del mismo. De igual forma, el entrevistado explica la tendencia de los aymaras a votar por candidatos de derecha considerando su trayectoria vertical.

...si bien la población indígena es alta, los que estábamos en esa lucha éramos una minoría. Te estoy hablando de no más de cien personas. El resto de los indigenas era una nebulosa, ¿me entiendes? Esos éramos los que estábamos conscientes de que estos cambios se tienen que dar en esos niveles, con negociaciones y acuerdos. Y clarito que mucha gente no está ni ahí a lo mejor con el cambio. Más pensando en nuestra gente indígena que, generalmente, es más adicta a mantener los cargos politicos. No a cambiarlos. Y eso nos da, hasta ahora, una razón, en el sentido que si tú vas a una elección en la zona rural, más votan por la derecha que por candidatos de la concertación o del área aliancista, ¿te das cuenta? ${ }^{8}$

Esta parte del testimonio apoya el análisis empírico precedente. Es decir, que el éxito de los candidatos de derecha es más visible en las comunas con alto porcentaje de población rural y con predominio de población indígena. De igual forma, se enfatiza en la atomización del movimiento indígena y en lo difícil que resulta institucionalizarlo. La satelización del movimiento indígena por los partidos, en tanto, es claramente retratada en la siguiente afirmación de Alfredo:

...y lo otro, a mi juicio también negativo, que está pasando mucho en este último tiempo, es que mucha gente que está en los niveles dirigenciales han tomado partido politico. Entonces, tienes gente de la concertación, gente de la derecha, a tal punto que en esta última elección -no se había dado antes-pero en esta última elección -en el caso de acá de Arica- tenemos el comando del pueblo Aymara por Frei, y a la semana siguiente, emerge el comando del pueblo Aymara por Piñera. Y me imagino que en el mundo Mapuche y Atacameño debe ocurrir algo similar, ¿te das cuenta?

Para Saida, nuestra segunda entrevistada, la intervención de los partidos explica la desintegración orgánica del movimiento indígena. Para ella, y en concordancia con el argumento anterior, los partidos son un verdadero tapón para la consolidación del movimiento.

... Me da mucha más pena, porque yo participé del movimiento indígena hasta el año 90 , que fue cuando me fui. Y vengo de lugares donde el sector indígena se juega la vida. En esos lugares, la demanda es por salud, educación, tierras, por un montón de cosas. Cuando yo llegué, no me había dado cuenta, pero vi que la gente se pelea por la plata. Están fragmentados por los intereses politicos. Y luego ven sus mediaguas o su plano familiar cercano, con el fin de sacar recursos. Hasta eso lo podría aceptar, siempre y cuando no perdieran el norte. Estamos frente a un movimiento indigena que está desarticulado. Pero fijate que esto es a nivel continental.

$\overline{\text { Los subrayados son nuestros, cuestión que también aplica para los siguientes fragmentos. }}$ 
Para Alejo, nuestro tercer entrevistado, la intervención de los partidos también ha evitado la consolidación del movimiento. Su énfasis está en el grado de división en la población aymara y en la carencia de un espíritu programático común.

...nunca podemos hablar de que aqui estamos los aymaras unidos. Siempre hemos estado divididos desde un principio. Esto lo vemos con los jóvenes que formaron el Pacha Aru, que ahora se unieron a los partidos politicos. Me acuerdo que en un tiempo entraron como 10 al PPD. Y ahí están. A veces traicionando a sus propios hermanos de "raza". Otras veces en aras de cumplir con lo que dice el partido. Entonces por eso tengo una pésima impresión de los aymaras políticos.

El elemento en común de estos tres testimonios, entonces, consiste en el efecto negativo de la política partidaria en el mundo aymara para la generación de un movimiento político propio. Existe coincidencia en que la intervención de los partidos ha contribuido a fragmentar su etnicidad. Esto apoya los planteamientos teóricos revisados más arriba en torno a los determinantes de surgimiento y éxito de los partidos étnicos. A diferencia de otros países de la región como Bolivia y Ecuador, no sólo existen altas barreras de entrada para nuevos partidos debido al sistema electoral binominal, sino que también una alta nacionalización del sistema de partidos chileno que impide la emergencia de colectividades locales o subnacionales fuertes.

\section{Conclusión}

1 Este trabajo muestra la relevancia del control metodológico por territorio para el correcto análisis de los resultados electorales. Como revisamos, la relación lineal simple entre el porcentaje de población indígena y el voto por Sebastián Piñera es directa. Esto implica que a mayor concentración indígena, mayor voto por Piñera. Sin embargo, al controlar esta relación según región la situación cambia muy significativamente. En un modelo con efectos fijos, la relación entre porcentaje de indígenas y voto por la derecha no es significativa. Esto obedece, básicamente, a la especificación del modelo al incluir los impactos regionales. Las regiones que en mayor medida concentran población indígena son la Primera y Novena. No obstante, la relación entre ambas variables es distinta según cada zona. Esto nos retrata el efecto que tiene el tipo de población indígena sobre los resultados electorales. Mientras en las comunas con mayor concentración de población aymara el voto por Piñera aumenta, en las comunas con altos porcentajes de mapuches la relación no es tan clara. En la Novena la correlación es cercana a cero y en la Décima incluso llega a ser negativa.

2- Las explicaciones en torno a la tendencia electoral de comunas con predominio aymara y mapuche tienen raíces históricas. De acuerdo a la trayectoria de ambas comunidades, cuestión que se ve particularmente reflejada en las entrevistas a agentes políticos aymaras, la tendencia de voto hacia la derecha dice relación con la estructura de poder vertical de su organización política. Esto marca diferencias significativas con la organización mapuche, caracterizada históricamente por mayores niveles de horizontalidad. 
3 Adicionalmente, las diferencias se explican por el contexto espacial asociado a los niveles de urbanización. Mientras las comunas con predominio mapuche se han acercado paulatinamente a emergentes centros urbanos, las comunas con predominio aymara siguen recluidas a un espacio distante de dichos centros. Además, exhiben mayores porcentajes de población rural, lo que se explica por la vigencia de su estructura económico-productiva. Nos referimos específicamente a comunas tales como General Lagos, Colchane, Camiña y Putre, que concentran significativos porcentajes de población rural. Estamos conscientes de las limitaciones de los datos y de la movilidad y migración de esta población hacia las grandes urbes. Sin embargo, y a pesar de esta limitante, los datos mantienen la tendencia enunciada. Es decir, que en las comunas de alta concentración aymara los candidatos de derecha tienen un desempeño muy por sobre el promedio. Reconocemos la existencia de literatura que sostiene la hipótesis de la amplia urbanización del mundo aymara en ciudades como Arica, Iquique, Antofagasta y Santiago (Gundermann, 2001 y 2003a), pero esto no invalida las conclusiones a las que hemos arribado. Ciertamente, la población no es estática y hay movimientos significativos, pero esto no implica que las tendencias electorales sean independientes de variables asociadas a las características de la población que, en este caso, giran en torno al volumen de población indígena. IEURE

\section{Referencias bibliográficas}

Adams, R. (1978). La red de la expansión humana: un ensayo sobre energía, estructuras disipativas, poder y ciertos procesos mentales en la evolución de la sociedad humana. México: Nueva Imagen.

Altman, D. (2004). Redibujando el mapa electoral chileno: incidencia de factores socioeconómicos y género en las urnas. Revista de Ciencia Politica, Vol. XXIV, No. 2, pp. 49-66.

Assadourian, C.S. (1983). El sistema de la economia colonial: el mercado interior. Regiones y espacio económico. México: Nueva Imagen.

Bartolini, S. \& Mair, P. (1990). Identity, Competition and Electoral Availability. The Stabilization of European Electorates, 1885-1985. Cambridge: Cambridge University Press.

Bengoa, J. (2000). Historia del pueblo mapuche: (Siglo XIX y XX). Santiago: LOM Ediciones.

Bengoa, J. (2007). La emergencia indígena en América Latina. Santiago: Fondo de Cultura Económica.

Birnir, J. (2006). Ethnicity and electoral politics. New York: Cambridge University Press.

Campbell, A.; Converse, P.; Miller, W. \& Stokes, D. (1960). The American Voter. New York: John Wiley.

Castro, L. (2005). Regionalismo y Desarrollo Regional: Debate público, proyectos económicos y actores locales (Tarapacá 1880-1930). Viña del Mar: CEIP Ediciones, Universidad de Valparaíso-UST.

Cerda, R. (2009). Situación socioeconómica reciente de los mapuches en la región de La Araucanía. Estudios Públicos, No. 113, verano, PP. 27-107.

Coppedge, M. (1997). District magnitude, economic performance, and party-system fragmentation in five Latin American countries. Comparative Political Studies, Vol. 30, No. 2, pp. 156-185. 
De la Peña, G. (1995). La ciudadanía étnica y la construcción de los indios en el México contemporáneo. Revista Internacional de Filosofía Politica, No. 6, pp. 116-140.

Dowse, R. \& Hughes, J. (1971). The Family, the School, and the Political Socialization Process. Socio$\log y$ Vol. 5, No. 1, pp. 21-45.

Faúndez, J. (1992). Izquierdas y Democracia en Chile 1932 - 1973. Santiago: Ediciones Bat S.A.

Favre, H. (1996). El indigenismo. México: Fondo de Cultura Económica.

Fiorina, M. (1981). Retrospective Voting in American National Elections. New Haven: Yale University Press. Gil, F. (1969). El sistema politico de Chile. Santiago: Andrés Bello.

González, H. (2000). Identidad cultural aymara, nacionalidad y globalización. En S. Correa Sutil (Ed.). ¿Hay patria que defender? La identidad nacional frente a la globalización. Santiago: Centro de Estudios para el Desarrollo.

González, J.M. (2000). Lideres profesionistas y organizaciones étnicas-sociales. Rastros y rostros en la construcción de la p'urhepecheidad en Paracho. Tesis de maestría. CIESAS-Unidad Occidente.

González, J. (2006). Estado nacional en México, etnicidad indígena e identidad étnica: el caso de los intelectuales purhépechas. Cuadernos Interculturales, No. 6, pp. 55-92.

Grofman, B. (1995). Information, Participation and Choice. An Economic Theory of Democracy in Perspective. Ann Arbor: University of Michigan Press.

Gundermann, H. (2001). Procesos regionales y poblaciones indígenas en el norte de Chile. Un esquema de análisis con base en la continuidad y los cambios de la comunidad andina. Estudios Atacameños, No. 21, pp. 89-112.

Gundermann, H. (2003). Sociedades indígenas, municipio y etnicidad: la transformación de los espacios políticos locales andinos en Chile. Estudios Atacameños, No. 25, pp. 55-77.

Gundermann, H. (2003a). La formación del espacio andino en Arica y Tarapacá. Revista de Historia Indígena, No. 7, pp. 87-138.

Hidalgo, J. (1972). Culturas Protohistóricas del Norte de Chile: el testimonio de los cronistas. Santiago: Universitaria.

Hidalgo, R.; De Mattos. C \& Arenas, F. (Eds.) (2009). Chile: del país urbano al país metropolitano. Santiago: Colección EURE-Libros, Pontificia Universidad Católica de Chile.

Huneeus, C. (2006). La necesidad de la reforma electoral. En C. Huneeus (Ed.). La reforma al sistema binominal en Chile: una contribución al debate. Santiago: Konrad Adenauer.

Joignant, A. \& Navia, P. (2003). De la política de individuos a los hombres del partido. Socialización, competencia política y penetración electoral de la UDI (1989-2001). Estudios Públicos, No. 89, verano, pp. 129-172.

King, G.; Keohane, R. O. \& Verba, S. (1994). Designing Social Inquiry. Scientific Inference in Qualitative Research. Princeton: Princeton University Press.

Kosuke I.; King, G. \& Lau, O. (2007). Ls: Least Squares Regression for Continuous Dependent Variables. En I. Kosuke, G. King y O. Lau (Eds.). Zelig: Everyone's Statistical Software. Recuperado el 5 de febrero de 2008 del sitio web http://gking.harvard.edu/zelig.

Lameiras Olvera, J. (1985). Los Déspotas Armados. Zamora: COLMICH.

Lazarsfeld, P.; Berelson, B. \& Gaudet, H. (1944). The people's choice. How the Voter Makes Up his Mind in the Presidential Campaing. New York: Columbia University Press.

León, L. (1989). Pukaraes Incas y fortalezas indigenas en Chile central, 1470-1560. Londres: Institute of Latin American Studies, University of London. 
León, L. (1991). Maloqueros y Conchavadores en Araucania y las Pampas, 1700-1800. Temuco: Universidad de la Frontera.

Lewis-Beck, M.; Jacoby, W.; Norpoth, H. \& Weisberg, H. (2008). The American Voter Revisited. Ann Arbor: University of Michigan Press.

Lewis-Beck, M. \& Stegmaier, M. (2000). Economic Determinants of Electoral Outcomes. Annual Review of Political Science, No. 3, pp. 183-219.

Lewis-Beck, M. (1988). Economics and Elections. Ann Arbor: University of Michigan Press.

Lijphart, A. (1999). Patterns of Democracy - Government Forms and Performance in Thirty-Six Countries. New Haven and London: Yale University Press.

Lipset, S.M., \& Rokkan, S. (Eds.) (1967). Party Systems an Voter Alignment: Cross National perspectives. New York: Free Press.

López, M. \& Morales, M. (2005). La capacidad explicativa de los determinantes familiares en las preferencias electorales de los chilenos. Política, No. 45, pp. 87-108.

López, M. (2004). Conducta electoral y estratos económicos: el voto de los sectores populares en Chile. Política, No. 43, pp. 285-298.

Lynch, J. (1989). Las Revoluciones Hispanomaericanas: 1808-1826. Barcelona: Ariel.

Lynch, J. (1993). Caudillos en Hispanoamérica: 1808-1850. Madrid: MAPFRE.

Madrid, R. (2005). Ethnic cleavages and electoral volatility in Latin America. Comparative Politics, Vol. 38, No. 1, pp. 1-20.

Magar, E.; Rosemblum, M. \& Samuels, D. (1998). On the Absence of Centripetal Incentives in Double-Member Districts. The Case of Chile. Comparative Political Studies, Vol. 31, No. 6, pp. 714-739.

Miller, W. \& Shanks, M. (1996). The New American Voter. Cambridge: Harvard University Press.

Morales, M. \& Bugueño, R. (2001). La UDI como expresión de la nueva derecha en Chile. Estudios sociales, No. 107, pp. 215-248.

Morales, M. (2008). La primera mujer Presidenta de Chile: ¿qué explicó el triunfo de Michelle Bachelet en las elecciones de 2005-2006? Latin American Research Review, Vol. 43, No. 1, pp. 7-32.

Morales, M. (2009). Las elecciones municipales en Chile 2008: Bases electorales por coalición y efecto de la aprobación presidencial. Elecciones, Vol. 8, No. 9, pp. 159-186.

Murra, J. (1980). La organización económica del estado Inca. México: Siglo XXI.

Navia, P. (2005). La transformación de votos en escaños: leyes electorales en Chile, 1833-2004. Política y Gobierno, Vol. XII, No. 2, pp. 233-276.

Navia, P. (2007). El pluralismo y el arcoíris de la Concertación. Revista UDP Pensamiento y Cultura, Vol. 3 No. 5, pp. 17-22.

Palerm, Á. (1998). Antropología y marxismo. México: CIESAS.

Palerm, Á. (2007). Agua y Agricultura: Ángel Palerm, la discusión con Karl Wittfogel sobre el modo asiático de producción y la construcción de un modelo para el estudio de Meosamérica. México: Universidad Iberoamericana.

Percheron, A. \& Jenning, M. (1981). Political Continuities in French Families. A New Perspective on an Old Controversy. Comparative Politics, No. 13, pp. 421-436.

Rehren, A. (2000). Clientelismo político, corrupción y ética en la nueva democracia chilena. En P. Drake \& I. Jaksic. (Ed.). El Modelo Chileno. Democracia y desarrollo en los noventa. Santiago: LOM. 
Rice, R. \& Lee Van Cott, D. (2006). The Emergence and Performance of Indigenous Peoples' Parties in South America. A Subnational Statistical Analysis. Comparative Politics, Vol. 39, No. 6, pp. 709-732.

Scully, T. (1992). Los partidos de centro y la evolución política chilena. Santiago: CIEPLAN.

Sen, A. (2008). Identidad y violencia. La ilusión del destino. Buenos Aires: Katz Editores.

Siavelis, P. (2000). Continuidad y cambio en el sistema partidista chileno: sobre los efectos de transformación de una reforma electoral. Revista de Ciencia Política, Vol. XX, No. 2, pp. 82-102.

Smith, A. (1998). Nationalism and Modernism. A critical survey of recent theories of nations and nationalism. London-New York: Routledge.

Smith, A. (1999). Myths and memories of the nation. Oxford: University Oxford Press.

Soto, Á. (2001). La irrupción de la UDI en las poblaciones. 1983-1987. Trabajo preparado para ser presentado en la reunión anual de la LASA (Latin American Studies Association), Washington DC, Septiembre 6-8.

Torcal, M. \& Mainwaring, S. (2003). The Political Recrafting of Social Bases of Party Competition: Chile, 1973-95. British Journal of Political Science, No. 1, pp. 55-84.

Trejo, G. (2000). Etnicidad y Movilización Social. Una revisión teórica con aplicaciones a la cuarta ola de movilizaciones indígenas en América Latina. Politica y Gobierno, Vol. 7, No. 1, pp. 205-250.

Valenzuela, A. (1977). Political brokers in Chile: local government in a centralized policy. Durham, D.C: Duke University Press.

Valenzuela, A. (2003). El quiebre de la democracia en Chile. Santiago: Colección Ciencia Política Universidad Diego Portales.

Valenzuela, S. \& Scully, T. (1997). Electoral Choices and the Party System in Chile: Continuities and Changes. Comparative Politics, Vol. 29, No. 4, pp. 511-527.

Valenzuela, S. (1995). Orígenes y transformación del sistema de partidos en Chile. Estudios Públicos, No. 58, otoño, pp. 5-80.

Van Kessel, J. (1980). Holocausto al progreso: los aymaras de Tarapacá. Ámsterdam: Centro de Estudios y Documentación Latinoamericanos.

Vázquez León, L. (1992). Ser indio otra vez. La purepechización de los tarascos serranos. México: Consejo Nacional para la Cultura y las Artes.

Wolf, E. (1987). Europa y la gente sin historia. México: FCE.

Zárate Hernández, J. (1993). Los señores de utopia. Zamora: COLMICH-CIESAS-México. 